\title{
Phytomolecules Repurposed as Covid-19 Inhibitors: Opportunity and Challenges
}

\author{
Vaishnavi Chandramouli ${ }^{1} \cdot$ Shekhar Kumar Niraj ${ }^{1} \cdot$ Krishna G. Nair $^{2}$ · Jerrine Joseph ${ }^{3}$. Wilson Aruni ${ }^{4,5,6}$
}

Received: 9 January 2021 / Accepted: 20 August 2021 / Published online: 26 August 2021

(c) The Author(s), under exclusive licence to Springer Science+Business Media, LLC, part of Springer Nature 2021

\begin{abstract}
The SARS-CoV-2 virus has spread worldwide to cause a full blown pandemic since 2020. To date, several promising synthetic therapeutics are repurposed and vaccines through different stages of clinical trials were approved and being administered, but still the efficacy of the drugs and vaccines are yet to be decoded. This article highlights the importance of traditional medicinal plants and the phytomolecules derived from them, which possess in vitro antiviral and anti-CoV properties and further explores their potential as inhibitors to molecular targets of SARS-CoV-2 that were evaluated by in silico approaches. Botanicals in traditional medicinal systems have been investigated for anti-SARS-CoV-2 activity through in silico and in vitro studies. However, information linking structure of phytomolecules to their antiviral activity is limited. Most phytomolecules with anti-CoV activity were studied for inhibition of the human ACE2 receptor through which the virus enters host cells, and non-structural proteins $3 \mathrm{CL}^{\text {pro }}$ and $\mathrm{PL}^{\text {pro }}$. Although the proteases are ideal anti-CoV targets, information on plant-based inhibitors for the $\mathrm{CoV}$ structural proteins, e.g., spike, envelope, membrane, nucleocapsid required further investigations. In absence of scientific evaluations through in vitro and biocompatibility studies, plant-based antivirals fall short as treatment options. Plant-based anti-SARS-CoV-2 therapeutics can be promising alternatives to their synthetic counterparts as they are economical and bear fewer chances of toxicity, side effects, and viral resistance. Our review could provide a systematic overview of the potential phytomolecules which can be repurposed and subjected to further modes of experimental evaluation to qualify for use in treatment and prophylaxis of SARS-CoV-2 infections.
\end{abstract}

\section{Introduction}

Coronaviruses, a genus of the Coronaviridae family, are enveloped viruses with a large plus-strand RNA genome commonly associated with respiratory or enteric infections

Jerrine Joseph

jerrine.cddd@sathyabama.ac.in

1 Advanced Institute for Wildlife Conservation, Tamil Nadu Forest Department, Government of Tamil Nadu, Chennai 600048, India

2 MES T O Abdulla Memorial College, Kunnukara, Aluva, Kerala 683578, India

3 Centre for Drug Discovery and Development, Sathyabama Institute of Science and Technology, Chennai 600119, India

4 Sathyabama Institute of Science and Technology, Chennai 600119, India

5 School of Medicine, Loma Linda University, Loma Linda, CA, USA

6 Musculoskeletal Disease Research Laboratory US, Department of Veteran Affairs, Loma Linda, CA, USA in human, mammal, fish, and avian hosts [1, 2]. CoVs were initially known to be enzootic, causing disease only in animals hosts, although few CoVs have crossed the animal-human species barrier and progressed to cause zoonoses in humans. The novel corona virus disease, COVID-19, caused by SARSCoV-2 virus started as an endemic flu type epidemic, causing pneumonia, in December 2019 in the Hubei province of China with Wuhan city as the epicenter of the infection. Presently, the virus has spread as a full blown pandemic across the globe manifesting major clinical symptoms such as dry cough, fever, diarrhea, breathlessness, and fatigue, with many patients developing dyspnea and lymphopenia. The disease progression is associated with complications such as respiratory distress syndrome, acute cardiac injury, and RNaemia [3]. Although vaccines and antivirals for treatments are being fast-tracked by regulatory agencies in various countries, their effects in the long term will not be known yet. To date, no perfect therapeutics have been approved against any human-infecting coronaviruses and all their variants $[4,5]$. The susceptibility of populations to SARS-CoV-2 is presently under investigation. Older people and people with pre-existing disease 
conditions such as asthma, hypertension, heart disease, and diabetes are at higher risks of developing severe illness as a result of infection [6]. However, COVID-19 has slain more people than any other coronaviruses, such as, SARS-CoV and MERS-CoV [7]. In the course of running preventive measures, countries remain administratively crippled and grapple with fear of their economy sliding down, their citizenry losing jobs coupled with the anxiety of losing human lives at mass scale. Viral diseases pose high risks to the human health on account of the highly mutative nature of the viral genomes, making it difficult to control transmission and in coming forward with effective interventions [8]. Despite constant advances in the drug discovery process and discovery of novel antiviral agents, most treatments for viral diseases include synthetic drugs of which action is non-specific for particular viruses [9]. While synthetic antivirals help in bringing the infection under control, they could cause undesirable side effects coupled with their inability in changing the course of induced viral complications. Developed inefficiency of the antivirals is attributed to the limited effective life span of synthetic antivirals, caused by problems of latency and recurrence in immune-compromised hosts [10].

Demand for alternative sources of antivirals has led to a revived interest in investigating natural, plant-based sources, which have advantages of being much less expensive, having better patient tolerance, and fewer or no side effects. In India, traditional medicines have been practiced through ages. India, like China, has a diverse medicinal plant system that has diverse sources of therapeutic agents, which have proved useful for combating viral disorders. Plant-based formulations to treat historic epidemics have been previously reported in the case of $\mathrm{CoV}$, influenza, and dengue viruses [11]. Medicinal plants exert antiviral effects and enhance the immune system. Indian medicinal plants have been widely studied for a range of therapeutic applications and their use in medicines since ancient times. Listed in Ayurveda, Siddha, and Unani medicine systems in India, their investigations can be the key to alleviate pathologies caused by viruses and in overcoming the limitations of existing antivirals. Several studies on the antiviral activity of plants against different CoVs, and other enveloped viruses that cause diseases in humans have been reported. In view of the present pandemic, our review aims to focus on the potential phytomolecules that can be repurposed as inhibitors for molecular targets of SARS-CoV-2 and its variants by making use of the information obtained through previously conducted investigations.

\section{Biology of Coronaviruses-Extrapolating Known Data to Determine Pathogenesis of SARS-CoV-2}

Coronaviruses belong to the order Nidovirales, family Coronaviridaeand sub-family Coronavirinae. Their genome size is approximately $26-32 \mathrm{~kb}$, which is the largest known size for RNA viruses [12] and are associated with a GC content of 32-43\% [2]. SARS-CoV, MERS$\mathrm{CoV}$, and SARS-CoV-2 belong to betacoronaviruses and are further classified under the Sarbecovirus subgenera. The recently emerged SARS-CoV-2 virus possesses 79.5\% identity to SARS-CoV, $51.8 \%$ to MERS-CoV, and $96.2 \%$ identity to bat (i.e., order Chiroptera) CoV [13, 14]. Phylogenetic analysis, using the publicly available SARS-CoV-2 sequences yielded $86.9 \%$ sequence identity with previously published sequence of bat SARS-like CoV, while Simplot analysis yielded $96 \%$ identity with that of bat $\mathrm{CoV}$ isolate RaTG13, suggesting a probable origin from bats [2]. Major structural proteins (e.g., spike, nucleocapsid, envelope, and membrane) and non-structural proteins of CoV play significant roles in attachment to host cells and in pathogenesis. Structural proteins are encoded by one-third of the genome at the 3' end, while two-thirds of the genome at the $5^{\prime}$ end contain two ORFS $(1 \& 2)$. The non-structural proteins $\mathrm{M}^{\text {pro }}$ (Chymotrypsin-like protease or $3 \mathrm{CL}^{\mathrm{pro}}$ ) and Papain-like protease $\left(\mathrm{PL}^{\text {pro }}\right)$, produce 16 mature non-structural proteins, which further produce accessory proteins responsible for viral replication and transcription [2].

Spike protein is the first of the structural proteins involved in mediating attachment of virus to the receptors on host cell, and is responsible for causing subsequent fusion between viral and host cell membranes and finally allows viral entry into the host cell. Enhanced binding affinity between the spike glycoprotein of SARS-CoV and hACE2 receptor accounts for the increased transmissibility and disease severity observed in humans,, suggesting that it can spread as efficiently as demonstrated by the number of human-human transmission events. However, SARS$\mathrm{CoV}-2$ is unique due to the presence of a furin cleave site at the $\mathrm{S} 1 / \mathrm{S} 2$ boundary [5], which could largely affect its infective and transmissible characteristics. The nucleocapsid protein has a supposed role in viral assembly and budding, and is responsible for binding to CoV RNA genome, which is stabilized by binding to membrane protein. The nucleocapsid protein also mediates in the CoV replication cycle. Membrane protein along with the envelope protein makes up the viral envelope, whose interaction has been reported to suffice for production and release of virus-like particles. The envelope protein is the smallest major structural protein whose role is extremely significant 
as its absence impedes viral production and maturation [12]. Among the non-structural proteins, the active site of Mpro has been identified to be highly conserved among CoVs with several shared common features [14]. Homology of $\mathrm{M}^{\text {pro }}$ has been evidenced in its primary amino acid sequence as well its tertiary structure [15]. It is interesting to note that $\mathrm{M}^{\text {pro }}$ does not possess a human homolog, thus making it an ideal antiviral target [14].

The present genomic data suggests that SARS-CoV-2 bears sequence identity to SARS-CoV to an extent that the therapeutics investigated for it can be repurposed and repositioned for the treatment of SARS-CoV-2. Although the pathogenesis and exact biology of SARS-CoV-2 is yet to be determined, the present knowledge pertaining to SARS$\mathrm{CoV}$ and MERS-CoV can provide important clues for the present and future research efforts into the investigation of SARS-CoV-2.

\section{Antiviral Approaches}

\section{Potential Antiviral and Immunomodulatory Phytomolecules}

Use of medicinal plants in prevention and treatment of respiratory viral infections is an age-old practice owing to their immune stimulation and inflammation modulating effects in addition to exhibiting antiviral properties. In SARS-CoV-2 infections, lung damage and respiratory insufficiency are most often caused by the inflammatory injury to alveolar capillaries due to the generalized cytokine storm, chemokines, and inflammatory cytokines. An important strategy to protect lung damage from effects of viral infection could be to explore antiviral plants reported to possess inhibitory activity against known pathogenic viruses, which also possess immune modulatory properties thereby acting as enhanced therapeutic agents [16]. Search for medicinal plants with reported antiviral and immune modulatory (e.g., anti-inflammatory, controlling cytokine production, and immune boosting) properties will serve as mode of treatment and prophylaxis for SARS-CoV-2 infection by directing the immune system to control the inflammatory response to the invading virus and inhibiting viral propagation in the cells. We have conducted an overview of reported plantbased antivirals proven to inhibit pathogenic viruses, use of the plants in traditional medicinal systems, and their associated immune modulatory effects that produce a controlled immune response against enveloped and respiratory disease causing viral pathogens previously recorded (Table 1). The phytomolecules such as baicalin, rhein, chebulagic acid, glycyrrhizin, betulinic acid, and andrographolide have demonstrated anti-viral activity against enveloped and respiratory disease causing viruses such as HIV, dengue, HSV, IAV.
Although phytomolecules such as glycyrrhizin, baicalin, rhein, and betulinic acid have been studied for inhibition of coronaviruses, data on uses of the source plants of the aforementioned phytomolecules in traditional medicinal systems have also been collated and will be critical for investigating the plants for symptomatic treatment of SARS-CoV-2 infected patients. The medicinal plants listed can be explored for possessing specific inhibitory and immune regulatory properties and repurposing for use against SARS-CoV-2.

\section{Plants/Phytomolecules Reported to Possess Antiviral Activity Against CoV}

\section{Inhibitors of Various CoV In Vitro}

Dried roots and rhizomes of Glycyrrhiza glabra L. contain bioactive phytomolecules glycyrrhizin (triterpine) and $18 \beta$ glycyrrhetinic acid (aglycone) [17, 18]. Although the exact mechanism by which these molecules exert their antiviral activity is unknown, adsorption and penetration of SARS$\mathrm{CoV}$ was inhibited during the early stages of the viral replication cycle. Glycyrrhizin has the ability to interfere with viral signal transduction and resulting in up-regulation of NO production, which also has antiviral properties, thus exerting immunomodulatory and protective activity [19]. Immunomodulatory effects of glycyrrhizin could be established by its use in the treatment of chronic viral infections along with L-cysteine and glycine. Antiviral activity against SARS-CoV was demonstrated by active principles from plants, e.g., ginsenoside Rb1 from Panax ginseng C.A. Mey, aescin from horse chestnut tree Aesculus hippocastanum L., and reserpine from Rauwolfia sp. P.ginseng is widely used in TCM for treatment of spontaneous sweating and fever, atrophic lung disease and phlegm, shortness of breath, and providing nourishing and immune-enhancing effects among many other uses [20, 21].

Flavonoid catechin isolated from Eleutherococcus senticosus (Rupr. \& Maxim.) Maxim. demonstrated anti-CoV activity, while the alkaloids cepharanthine and isoquinoline isolated from Stephania cephalantha Hayata and flavonoid baicalin isolated from $S$. baicalensis displayed effective anti-SARS-CoV activity in vitro [10, 22]. Plant extracts using whole plant of Artemisia annua L., leaf of Pyrrosia lingua (Thunb.) Farw., root of Lindera aggregate (Sims) Kosterm., and the phytomolecule lycorine from Lycoris radiata (L'He'r.) Herb.demonstrated significant anti-SARS$\mathrm{CoV}$ activity in vitro [23]. Plant extracts of Artemisia annиa L. inhibited feline coronavirus and SARS-CoV-2 in vitro, with its activity attributed to artemisinin and other flavonoids present in the extract [24, 25]. Phytomolecules UDA ( $\mathrm{U} d$ agglutinin) from the plant Urtica dioica $\mathrm{L}$, represented a moderately active antiviral lectin with increased therapeutic utility by specifically interacting with oligomers at the 


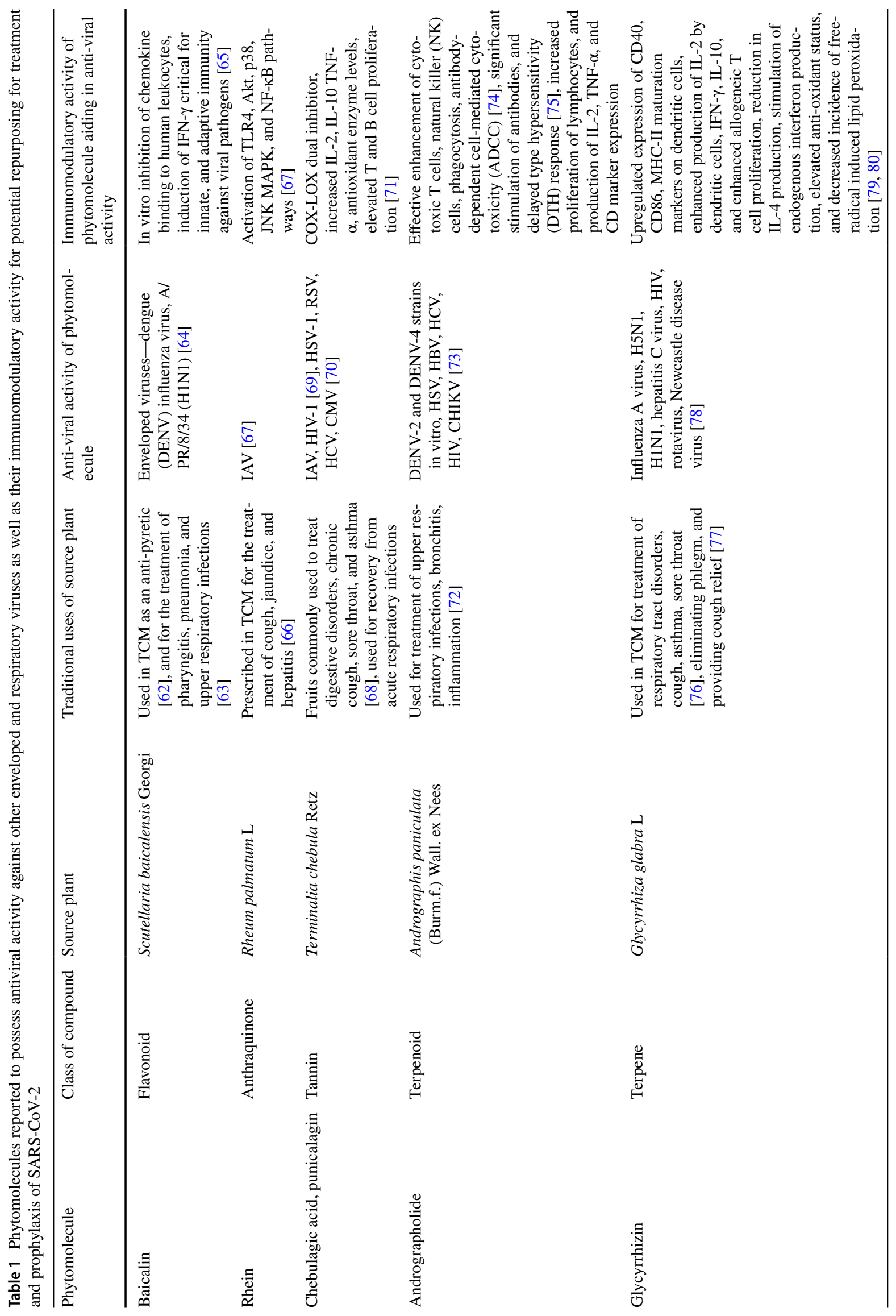




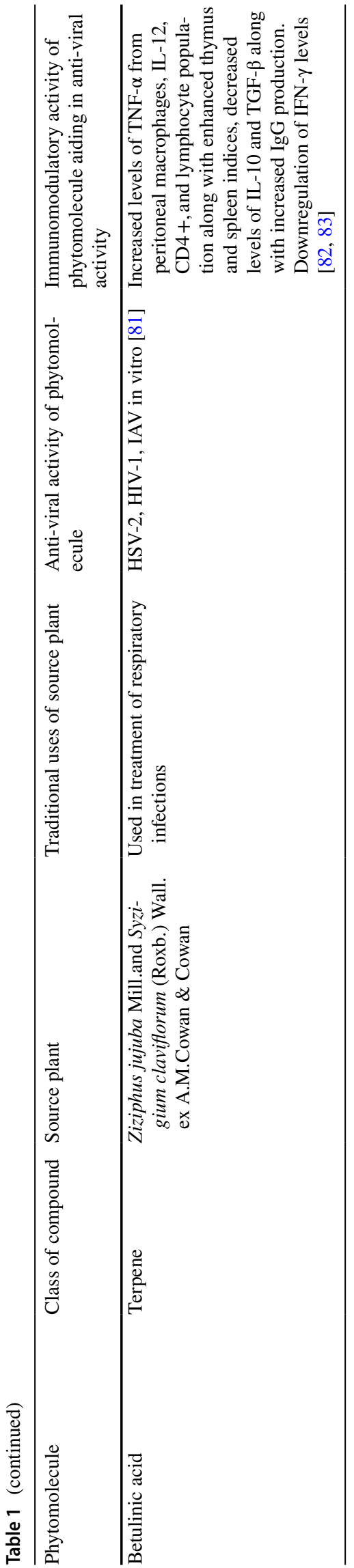

core of glycans and homologous envelope proteins of SARSCoV. In an in vivo experiment, UDA was able to protect mice against lethal infection, protect against weight loss, and decreased lung pathology scores. However, it did not reduce lung viral titres [26].

A number of plant extracts and associated phytomolecules exhibited antiviral activity against the viruses other than SARS-CoV, e.g., MERS-CoV, HCoV-229E murine coronavirus. Resveratrol (trans-3', 5, 4'-trihydroxystilbene), abundant in plants such as grape (Vitis vinifera L.), huzhang (Polygonum cuspidatum Siebold \& Zucc.), and cranberry (Vaccinium macrocarpon Aiton), inhibited viral growth of MERS-CoV. The phytomolecule was able to prolong cellular survival after viral infection and resulted in decreased expression of nucleocapsid protein in a dose-dependent manner [27]. Silvestrol, a type of flavagline from the genus Aglaia, was identified to be an eIF4A (DEAD box RNA helicase) inhibitor. Silvestrol displayed antiviral activity against MERS-CoV and $\mathrm{HCoV}-229 \mathrm{E}$ by inhibition of formation of viral replication or transcription complexes [28]. Antiviral activity of saikosaponins A, $\mathrm{B}_{2}, \mathrm{C}$, and D was reported against $\mathrm{HCoV}-229 \mathrm{E}$ by inhibition of viral attachment and penetration [29]. Quercetin, one of the most widely reported phytomolecules, inhibited propagation of murine coronavirus possibly by inhibiting $\mathrm{H}^{+}$-ATPase of lysosomal membrane and inhibition of viral coat protein removal [30]. Anti-SARS-CoV, MERS-CoV, and anti-HCoV229E activity was conducted by the commercial plant extract Echinoforce, derived from Echinacea purpurea (L.) Moench [31]. The phytomolecules with antiviral activity against coronaviruses were recorded in Table 2.

\section{Inhibitors of SARS-CoV Structural Proteins}

Potent anti-SARS-CoV activity was demonstrated by phytomolecule luteolin found in the plant used in TCM, e.g., Perilla frutescens (L.) Britt, which is traditionally used for treatment of asthma, cough, flu, cold, phlegm, stuffy nose, and headache [32]. Luteolin bound to $S 2$ subunit of the precursor of spike protein and blocked viral entry by interfering with the viral-host cell fusion process. Mannose-specific plant lectins from Galanthus nivalis L., and Allium porrum L. are promising anti-SARS-CoV agents. The anti-SARS$\mathrm{CoV}$ activity of mannose-specific plant lectins could be attributed to their ability to bind with mannose type glycans which form 2 of the $4 \mathrm{~N}$-glycosylation sites in SARS-CoV spike protein [33]. The anthraquinone emodin from plants of Genus Rheum and Polygonum block spike protein and ACE interaction in a dose-dependent manner [34]. Griffithsin, isolated from the red alga Griffithsia sp. is a $12.7 \mathrm{kDa}$ protein, which inhibits SARS-CoV viral entry both in vitro and in vivo by binding specifically to the spike glycoprotein [35]. Spike protein mediated binding and entry of SARS-CoV-2 
Table 2 Phytomolecules reported to possess antiviral activity against Coronaviruses

\begin{tabular}{|c|c|c|c|c|}
\hline Phytomolecules & Class of compound & Source plant & Antiviral activity against $\mathrm{CoV}$ & References \\
\hline Glycyrrhizin & Terpene & Glycyrrhiza glabra & SARS-CoV & {$[17]$} \\
\hline ginsenoside $\mathrm{Rb} 1$ & Triterpene saponin & Panax ginseng & SARS-CoV & {$[84]$} \\
\hline Aescin & Saponin & Aesculus hippocastanum & SARS-CoV & [84] \\
\hline Aurintricarboxylic acid & $\begin{array}{l}\text { Polyarmoatic carbox- } \\
\text { ylic acid derivative }\end{array}$ & & SARS-CoV & {$[85]$} \\
\hline Reserpine & Alkaloid & Rauwolfia sp. & SARS-CoV & [84] \\
\hline Catechin & Flavonoid & Eleutherococcus senticosus & $\mathrm{CoV}$ & {$[10]$} \\
\hline Cepharanthine and isoquinoline & Alkaloid & Stephania cepharantha & SARS-CoV & {$[10]$} \\
\hline Baicalin & Flavonoid & Scutellaria baicalensis & SARS-CoV & {$[22]$} \\
\hline Lycorine & Alkaloid & Lycoris radiata & SARS-CoV & {$[23]$} \\
\hline Alpha-hederin (glycyrrhizin derivative) & Triterpenoid saponin & Glycyrrhiza glabra & SARS-CoV & {$[86]$} \\
\hline UDA & Lectin & Urtica dioica & SARS-CoV & {$[26]$} \\
\hline Resveratrol & Polyphenol & $\begin{array}{l}\text { Vitis vinifera, Polygonum } \\
\text { cuspidatum and Vaccinium } \\
\text { macrocarpon }\end{array}$ & MERS-CoV & {$[27]$} \\
\hline Silvestrol & Benzofuran & Aglaia spp. & $\begin{array}{l}\text { MERS-CoV, } \\
\text { HCoV-229E }\end{array}$ & {$[28]$} \\
\hline Saikosaponins A, B $, \mathrm{C}, \mathrm{D}$ & Triterpene glycosides & Bupleurum spp. & HCoV-229E & [29] \\
\hline Theaflavins & Tannins & Black tea & Bovine coronavirus & {$[10]$} \\
\hline Quercetin & Flavonoid & & Murine coronavirus & {$[30]$} \\
\hline Echinoforce & & Echinacea purpurea & $\begin{array}{l}\text { SARS-CoV, } \\
\text { MERS-CoV, } \\
\text { HCoV-299E }\end{array}$ & {$[31]$} \\
\hline
\end{tabular}

was inhibited in vitro by a novel polyphenol brazilin as well as phytomolecules theaflavin-3,3 digallate and cucurmin [36]. We examined details of phytomolecules that exhibited inhibitory properties of the SARS-CoV structural proteins (Table 3).

\section{Inhibitors of SARS-CoV Non-structural Proteins}

The plant extract of Houttuynia cordata Thunb., traditionally used in India to treat fever and cough [37], demonstrated effective inhibition of $3 \mathrm{CL}^{\text {pro }}$ and $\mathrm{RdRp}$ in vitro. Upon further investigation, the immunostimulatory effect of the extract was identified. In uninfected cells, the extract prevented infection by virus by stimulating proliferation of CD4+ helper T cells and CD8+ cytotoxic T cells. In infected cells, the extract caused inhibitory effect against viral replication by hindering the activity of pivotal viral enzymes [38]. Root of Isatis indigotica Fortune ex Lindl., which is traditionally used in China for treatment of viral diseases, e.g., influenza, hepatitis, and encephalitis [39], was used to effectively inhibit SARS-CoV $3 \mathrm{CL}^{\text {pro }}$ due to the activity of its constituent phytomolecules, indigo, sinigrin, and $\beta$-sitosterol. Since $3 \mathrm{CL}^{\text {pro }}$ is a chymotrypsin-like protease, the established activity of indigo as a chymotrypsin inhibitor is justified [40]. Root of I.indigotica was patented as an herbal drug and the decoction was recommended by the National Health Commission of China in its treatment plan for SARS-CoV-2 in 2020 [41]. Other phytomolecules that exhibit inhibition against $3 \mathrm{CL}^{\text {pro }}$ include amentoflavone isolated from Torreya nucifera (L.) Siebold \& Zucc., myricetin,
Table 3 Phytomolecules as inhibitors of SARS-CoV structural proteins

\begin{tabular}{lllll}
\hline \multicolumn{2}{l}{ SARS-CoV structural protein inhibitors } & & & \\
\hline Phytomolecule & Class of compound & Target protein & Source plant & References \\
\hline Luteolin & Flavonoid & Spike & & {$[22]$} \\
Mannose-specific lectins & Lectin & Spike & $\begin{array}{c}\text { Galanthus nivalis, Hippeas- } \\
\text { trum hybrid, and Allium }\end{array}$ & {$[33]$} \\
& & & porrum \\
Emodin & Anthraquinone & Spike & Genus Rheum and Polygonum & {$[34]$} \\
Griffithsin & Protein & Spike & Griffithsia sp. (red alga) & {$[35]$} \\
\hline
\end{tabular}


and scutellarein [29]. Ethyl acetate fractions of heartwood of Chamaecyparis obtusa var. formosana (Hayata) Hayata yielded active components, ferruginol, and savinin, while ethyl acetate fractions of heartwood of Juniperus formosana Hayata yielded active constituents, betulonic acid, and forskolin. Among the aforesaid phytmolecules, betulonic acid and savinin demonstrated most effective competitive inhibition of $3 \mathrm{CL}^{\text {pro }}$ [42]. $3 \mathrm{CL}^{\text {pro }}$ inhibitory properties were demonstrated by 4 quinone-methide triterpenes from the plant Tripterygium regelii Sprague \& Takeda [43]. Herbal extracts of rhizome Cibotium barometz (L.) J.Sm. and Dioscorea batatas Decne., seeds of Gentiana scabra Bunge and Cassia tora $\mathrm{L}$. as well as stem with leaves of Taxillus chinensis (DC.) Danser inhibited SARS-CoV. Herbal extract derived from the rhizome of $D$. batatas, which exerted antiviral activity through inhibition of $3 \mathrm{CL}^{\text {pro }}$ was considered highly potent [44].

PLprotease of coronaviruses is an important target for antivirals as it is a significant non-structural protein that catalyzes its own release and liberation of other non-structural proteins from the polyprotein, without which the virus-mediated RNA replication could not occur. PL ${ }^{\text {pro }}$ also cleaves ubiquitin chains and causes deISGylation, thus highlighting its role in modifying host immune response to viruses. $\mathrm{PL}^{\text {pro }}$ inhibitors have been widely reported from different plant sources. Natural compounds exhibiting $\mathrm{PL}^{\text {pro }}$ inhibition include diaryl heptanoids, tanshinones, flavonoids, and cinnamic amides. These compounds form the base from which $\mathrm{PL}^{\text {pro }}$ inhibitors can be derived. Novel, active flavonoids from the TCM plant Paulownia tomentosa Steud. were reported to inhibit PL ${ }^{\text {pro }}$ of SARS-CoV due to the presence of a 3,4-dihydro- $2 \mathrm{H}$ pyran moiety. The flavonoids possessed a geranylated structure and were named tomentin A, B, C, D, E; of which tomentin B produced highest activity against $\mathrm{PL}^{\text {pro }}$. Other flavonoids from P.tomentosa, which displayed significant inhibition, include 3'-O-methyldiplacol, 4'-O-methyldiplacone, mimulone, and diplacone [45]. Tannic acid, theaflavin-3'-gallate, and theaflavin-3',3'-digallate from black tea leaves demonstrated anti-SARS-CoV activity by inhibition of $\mathrm{PL}^{\mathrm{pro}}[10]$. Xanthoangelol $\mathrm{E}$ was found to be one of the most active principles from the plant Angelica keiskei (Miq.) Koidz. Along with Xanthoangelol E, Xanthoangelol F, D, B, G, isobavachalcone, 4-hydroxyderricin, and Xanthokeistal demonstrated notable inhibition of $\mathrm{PL}^{\text {pro }}$ of SARS-CoV [46]. The active principles from A.keiskei were able to inhibit the activity of $3 \mathrm{CL}^{\text {pro }}$ and $\mathrm{PL}^{\text {pro }}$, thus, exhibiting anti-SARS-CoV activity through multiple mechanisms. Plant-based inhibitors of non-structural CoV proteins were analyzed and listed in Table 4. Docking studies demonstrated withanoside from the source plant Withania somnifera (L.) Dunal inhibited $3 \mathrm{CL}^{\text {pro }}$ and spike proteins of SARS-CoV-2 [47]. The inhibition was brought about by increase in IFN- $\gamma$ response and anti-inflammatory activities by decreasing IL-1, IL-6, and TNF- $\alpha$ levels [48]. The SARSCoV-2 $3 \mathrm{CL}^{\text {pro }}$ protein was also inhibited by Tinosponone from Tinospora cordifolia (Willd.) Miers [49] by modulation of cytokine production levels and activation of immune effector cells [48].

\section{Inhibitors of SARS-CoV-2 Target Receptor-ACE2}

The angiotensin converting enzyme II (ACE2) is a membrane bound enzyme located in the heart, kidney, vascular system, and digestive tracts. Studies on binding of SARSCoV-2 to human cells have demonstrated highest affinity of the virus toward human ACE2 receptor, which serves as the key bridge used by the virus for transmission between humans. Despite a $72 \%$ structural similarity of the spike glycoprotein RBD between SARS-CoV and SARS-CoV-2, RBD of the latter demonstrated higher interaction with the ACE2 receptor, which could explain the higher rates of transmissibility of SARS-CoV-2 compared to SARS-CoV. Understanding the importance of the receptor in facilitating viral entry into human cells, several studies have led to the discovery and repurposing of inhibitors of ACE2 receptor. The inhibitors function by altering the binding site of the virus on ACE2, thereby blocking virus-host cell interaction and virus binding. Although ACE2 inhibitors are potential
Table 4 Phytomolecules as inhibitors of SARS-CoV nonstructural proteins

\begin{tabular}{|c|c|c|c|}
\hline Phytomolecule & Class of compound & Source plant & References \\
\hline \multicolumn{4}{|l|}{ SARS-CoV 3CL ${ }^{\text {pro }}$ or $\mathrm{M}^{\text {pro }}$ inhibitors } \\
\hline Indigo, Sinigrin, and $\beta$-sitosterol & & Isatis indigotica & {$[40]$} \\
\hline Amentoflavone & Flavonoids & Torreya nucifera & {$[43]$} \\
\hline Ferruginol and savinin & Terpenoid and lignin & $\begin{array}{l}\text { Chamaecyparis obtusa } \\
\text { var. formosana }\end{array}$ & [44] \\
\hline Betulonic acid and Forskolin & Terpene & Juniperus formosana & [44] \\
\hline \multicolumn{4}{|l|}{ SARS-CoV PL ${ }^{\text {pro }}$ inhibitors } \\
\hline Tomentin B & Coumarin & Paulownia tomentosa & [45] \\
\hline Xanthoangelol E & Chalcone & Angelica keiskei & [46] \\
\hline Theaflavin-3',3'-digallate & Tannin & Black tea & {$[10]$} \\
\hline
\end{tabular}


agents to prevent SARS-CoV-2 infection, it is important to investigate if inhibition of ACE2 activity could impair recovery from infection [50] and identify if alternate antiinflammatory and antioxidant pathways are activated. Plants such as Allium sativum L., Cerasus avium L., Alcea digitata (Boiss.) Alef, and Rubia tinctorum L. have been reported to possess anti-ACE2 activity and can be explore for inhibition of ACE2 in SARS-CoV-2 [51]. Specific phytomolecules have been reported to inhibit ACE2 receptor, which serve as potent anti-SARS-CoV-2 agents (Table 5). The flavonoid class of compounds has yielded a maximum number of phytomolecules which demonstrated ACE2 inhibition. It is to be noted that phytomolecules, such as, luteolin, quercetin, rhein, glycyrrhizin, and emodin [52], which have demonstrated anti-CoV activity through inhibition of structural and non-structural proteins have also displayed ACE2 inhibition. Details of phytomolecules highlighted in this study could throw light on plant-based therapeutics, which would have heightened anti-SARS-CoV-2 potential by means of inhibition of binding to human receptor ACE2 and inhibition of viral protein targets.

\section{In Silico Approach for Repurposing Reported Antiviral Phytomolecules}

In wake of the COVID-19 pandemic, several in silico studies have been reported screening synthetic drugs and phytochemicals, as attempts to bring to light the possible compounds that can act as efficient COVID-19 inhibitors. Computational studies help to identify potential compounds and speed up the process of making effective therapeutics available to meet the need of the hour. Drug repurposing ensures that the identified compounds have established safety profiles, and eliminated possibilities of harmful side effects. Repurposing of FDA-approved drugs and those under clinical trials for SARS-CoV and

Table 5 Phytomolecules as inhibitors of ACE2 receptor

\begin{tabular}{llll}
\hline Phytomolecule & Class of compound & $\begin{array}{l}\text { Method of } \\
\text { assessing } \\
\text { activity }\end{array}$ & References \\
\hline Kaempferol & Flavonoid & In vitro & {$[52]$} \\
Quercetin & Flavonoid & In vitro & {$[52]$} \\
Apigenin & Flavonoid & In vitro & {$[87]$} \\
Baicalin & Flavonoid & In silico & {$[88]$} \\
Scutellarin & Flavonoid & In silico & {$[88]$} \\
Glycyrrhizin & Terpenoid & In silico & {$[88]$} \\
Curcumin & Cucurminoid & In silico & {$[89]$} \\
Emodin & Anthraquinone & In vitro & {$[90]$} \\
Caffeic acid & Phenolic acid & In vitro & {$[91]$} \\
Nicotinamine & Peptide & In vitro & {$[92]$} \\
\hline
\end{tabular}

MERS-CoVs would be a favorable strategy for development of therapeutics for COVID-19 [53]. Currently, phase III clinical trials of a few drugs specific to RdRp (RNAdependent RNA Polymerase) or $3 \mathrm{CL}^{\text {pro }}$ is in progress. Need to consider repurposing of drugs for major structural proteins of COVID-19, e.g., spike and $\mathrm{M}^{\text {pro }}$, assumes critical importance.

Although prime focus of in silico studies is placed on repurposing FDA-approved synthetic drugs, phytochemicals were also screened for in silico docking to SARS-CoV-2 targets. It is understood that most synthetic drugs used as antivirals have toxic side effects in the long run, and considering the potential of plant-based antivirals several in silico studies focusing on repurposing bioactive phytomolecules have been conducted. Phytochemicals listed in TCM were screened in silico and active phytomolecules including myricitrin, methyl rosmarinate, and amaranthin were identified as $3 \mathrm{CL}^{\text {pro }}$ inhibitors of SARS-CoV-2 [54]. In silico approach was used to identify FDA-approved antiviral compounds and phytochemicals active against $\mathrm{M}^{\text {pro }}$ of COVID-19 through virtual screening. Andrographolide, a small molecule from the medicinal plant Andrographis paniculata (Burm.f.) Wall. ex Nees was identified to possess in silico inhibitory activity against $\mathrm{M}^{\text {pro }}$ of SARS-CoV-2 [55]. Andrographolide docked successfully on the site of inhibition of $\mathrm{M}^{\text {pro }}$ of COVID-19 and possessed highly soluble and remarkable pharmacodynamic properties. The in silico binding occurred with high accuracy and alignment occurred with Lipinski's rule, thus making it a potential candidate for use in a therapeutic drug against COVID-19. In silico studies, such as, molecular docking, target analysis, toxicity prediction, and ADME prediction using computational biology established andrographolide from A. paniculata as a potential inhibitor of the main protease of SARS-COV-2 $\left(3 \mathrm{CL}^{\text {pro }}\right.$ or $\left.\mathrm{M}^{\mathrm{pro}}\right)$. Computational approaches also predict that andrographolide may have good solubility, pharmacodynamics property, and target accuracy, thus making it a promising compound to pursue with in biochemical and cell-based assays, and to explore its potential for use against COVID-19. In silico analysis also yielded successful docking of andrographolide against the inhibitor region of the main protease of SARS-CoV-2 virus with docking score of $-3.09 \mathrm{kcal} / \mathrm{mol}$. The docking score showed effective binding when compared to synthetic compounds when they are docked against $\mathrm{M}^{\text {pro }}$ protein, e.g., disulfiram, tideglusib, and shikonin with the results of $-46.16,-61.79$, and $-17.35 \mathrm{kcal} /$ mol, respectively. The binding scores were higher when compared with the recently proposed combination of three drugs, namely, lopinavir, ostelmivir, and ritonavir whose binding scores were $-4.1,-4.65$, and -5.11 , respectively. This implied that the affinity was lower. The drug ability feasibility parse is weighed upon several criteria apart from the binding scores alone where andrographolide has an 
advantage as it is a natural molecule and satisfies Lipinski's rule significantly.

\section{Network Ethnopharmacology Approach to Identify Effects of Traditional Medicines}

Any drug, whether synthetic or natural, will possess inherent limitations when its action is directed toward a single target [56]. Bioactive phytomolecules in herbal formulations can modulate multiple targets in a living cell, which can be elucidated by the network ethnopharmacology approach. The approach provides a system-level understanding to the pathogenesis of a disease and the mechanism of action of herbal formulations on the disease. Network pharmacological studies are based on examining biological systems and monitoring their information pathway responses after systematic perturbation [57]. Mathematical models are used to define the structure and response of a system to a particular perturbation. Possible interactions of bioactive phytomolecules with molecular targets of disease networks can be defined by molecular docking-based network ethnopharmacology, which was used to study ayurvedic formulations in assessing the potential of Triphala in multiple disease management through multi bioactive-multi-target interactions [56]. Many diseases are caused by malfunction of multiple genes and the effect of products of faulty genes which disturb biological processes. Systems biology and network analysis show that diseases sharing biological processes could be treated by the same drug [58]. Such approach will be essential when devising herbal formulations to treat patients who are infected by COVID-19 with detected comorbidities, since it is a multi-compound, multi-target approach to deal with multifactorial diseases [56].

Network ethnopharmacology was used to identify the holistic mechanism of action of herbal formulations against viral diseases [56, 58]. Role of TCM in treatment of COVID19 was elucidated using network pharmacology analysis. Its effectiveness and possible molecular mechanism of TCM formulations were analyzed [59]. Using the method, herbal formulations were identified to directly suppress replication of viruses by targeting different key proteins in viral life cycle and to indirectly regulate host defense system. The method was useful to resist viral infection and alleviate symptoms of upper respiratory tract infections [58]. Bioactive compounds in herbal formulations have complicated interactions with cellular targets, thus making network ethnopharmacology a promising tool to elucidate multi-component, multi-target properties of traditional medicinal plants in treatment of COVID-19. Network ethnopharmacology can be used to determine the mechanism of pharmacological action, safety, toxicity and side effects of herbal formulations, and phytomolecules that can be repurposed.

\section{Challenges in Development of Phytotherapeutics}

Phytomolecules have established their potential as promising antiviral agents against $\mathrm{CoVs}$ including the SARSCoV-2 and its variants. The traditional folklore knowledge, transmitted from generation to generation, was attributed to the therapeutic indications of medicinal plants. However, due to the lack of scientific evaluation of in vitro studies, biocompatibility studies, ADMET profiling, dosage, pharmacokinetics, and elucidation of their mode of action, plant-based antivirals fall short as effective treatment options. If investigations along these lines can be carried out with the support agencies, such as the Ministry of AYUSH of the Indian government, which has been diligently attempting to provide funds for creating medicinal plant databases along with biomedical applications, development of a robust repository to tap significant data on viral diseases could be facilitated. Whole plant extracts or the molecules isolated from them, and purified, could serve the purpose of investigating repurposing. However, scaling up the process in case of plants that are rare and endangered species (RET) could be one major challenge in the course of exploring plant-based antivirals. This challenge, however, could be overcome by adopting tissue culture methods to meet demands of producing plant-based therapeutics. Very often, the plant extracts on the whole demonstrate antiviral activity instead of a single phytomolecule; in such cases, purity of the extract, dose determination and formulation could become inherent challenges. In a realistic scenario, a mixture of phytomolecules might also be able to produce an enhanced synergistic antiviral effect as opposed to using individual phytomolecules. The holistic effect of mixture of phytomolecules or the individual action of a single phytomolecule can be studied through network ethnopharmacology analysis to elucidate the mechanism of action and the safety profile of the herbal formulations. Further investigations in this aspect can help to characterize the pharmacological profile of plant-based antivirals and enhance the scientific basis for their use in treating the disease.

\section{Discussion and Conclusion}

Through our review, phytomolecules demonstrating in vitro, in vivo, or in silico activity against coronaviruses in general as well as against ACE2 receptor, the structural and non-structural targets were recorded. The record is aimed to provide a holistic overview of the phytomolecules that can be used as starting points to for investigation 
of plant-based therapeutics for SARS-CoV-2. We identified the major class of compounds reported as inhibitors of specific SARS-CoV-2 molecular targets (Table 6). Phytomolecules from different classes of compounds and from a wide variety of plant families may have significant biomedical values as antivirals. With advancements in medicinal chemistry, structures of bioactive phytomolecules have been extensively studied and elucidated. However, with regard to their role as antivirals, limited number of investigations have been conducted to link the structure of phytomolecules to their antiviral activities. Deeper analysis on the structure-activity relationships of reported plant compounds and the role of specific functional groups in effecting viral inhibition can be considered as study points for the future of plant-based discovery of antivirals. Research studies during the years 2000s and 2010s involving investigation of plant sources as antiSARS-CoV agents were focused on the inhibition of the non-structural proteins, 3CLpro and PLpro and spike and membrane structural proteins. Although these proteins are effective and ideal antiviral targets, there are gaps in information on plant-based interventions as inhibitors for alternative protein targets, e.g., envelope, nucleocapsid, and enzymes such as RNA-dependent RNA polymerase $(\mathrm{RdRp})$ and hemagglutinin esterase (HE). Numerous studied have emerged highlighting the potential anti-viral activity of phytomolecules mediated through inhibition of ACE2 receptor, thereby preventing virus attachment to host cell. Citing the critical importance of structural proteins and ACE inhibitors in $\mathrm{CoV}$ and SARS-CoV-2 infections, efforts to identify potent phytomolecules that play dual role of ACE2 inhibition and inhibition of SARS$\mathrm{CoV}-2$ protein targets can be taken up to bridge the knowledge gap. The onset of pandemic saw a rise in publication of innumerable in silico studies that screened through libraries of phytomolecules and identified binding ability with molecular targets of SARS-CoV-2. More number of in vitro studies and plant therapy-based clinical trials are required to further validate the data obtained through in silico studies which can pave way for systematic use of phytotherapy for SARS-CoV-2 treatment.

The highly infectious and transmissive nature of SARS$\mathrm{CoV}-2$ has led to catastrophic ramifications on the polity and economies of various countries. Importance of finding workable solutions could not be overemphasized. Although the genome of SARS-CoV-2 has been mapped and its biology as well as etiology have been elucidated, the mechanism of zoonotic spillover of the virus causing it to result in this global pandemic is still being investigated. The first resort to treatment included several synthetic antimalarial and anti-HIV drugs being repurposed. Challenges of vaccine development against viruses will ever remain open. Examples of HIV, influenza, SARS-CoV, MERS-CoV, among several others, testify to the challenges. Vaccine against viruses offer limited degree of cross protection mainly due to extensive diversity among the antigenic variants. Besides, not all $\mathrm{CoV}$ genes are recombinant molecules. The complete genome sequence of HCoV-NL63 indicated that this virus was not a recombinant, but rather a new group 1 Coronavirus [60]. Human population density causes particular problems in exemplification of early mutation and structural changes due to large variations. The second surge in COVID-19 testifies to this fact amply. The extensive diversity was observed even among the strains belonging to the same phylogenetic sub-cluster [2]. With the emergence and re-emergence of new and old viral infections constantly posing a growing challenge to the survival of mankind [61], there is a constant demand for novel antiviral agents that are more economical, accessible and bear fewer chances of toxicity and viral resistance.

However, the toxic side effects exerted by synthetic drugs can be circumvented using plant-based-natural therapeutics. With studies conducted by investigating plant-based therapeutics for $\mathrm{CoV}$ treatment spanning over two decades, a

Table 6 Major class of compounds reported as inhibitors of specific SARS-CoV-2 molecular targets

\begin{tabular}{llll}
\hline Phytomolecule & Class of compound & SARS-CoV-2 target & References \\
\hline Amentoflavone & Flavone & GLN493, SER494, and GLY496 AAR & [93] \\
Baicalin & Flavone & $\mathrm{M}^{\text {pro }}$ pocket 2 & [94] \\
Bismahanine & Alkaloid & GLU406 (Spike protein) & [93] \\
Coagulins and Withanolides & Triterpenoids & AAR (Spike protein) & [93] \\
Curcumin & Polyphenols & Helicase pocket 32 & [94] \\
Farnesol & Terpenoid & Spike pocket10 & [94] \\
Graecunin E & Saponins & THR415 and GLN493 AAR (Spike protein) & [93] \\
Kamalachalcone C & Chalcone & GLN493, GLN492, ARG403, and GLU406 AAR \\
Pseudojervine & Alkaloid & AARs GLN493, GLY496 and SER494 of spike protein \\
Theaflavin & Catechins & Spike pocket 19 & [93] \\
Urosolic acid & Terpenoid & Nsp14 pocket 2 & [94] \\
\hline
\end{tabular}


promising plant-based cure for SARS-CoV-2 may see the light if characterized by in silico, in vitro, in vivo studies with special emphasis on its biocompatibility studies elucidating its pharmacological and toxicological profiles. In developing countries, community practice of using local medicines and drug formulations clearly evinced improved immunity against viruses. Chinese pharmacopeia, one of the most traditional yet well founded traditional medicinal practice, which established the TCM system, has been an important part of Chinese citizenry health system for centuries and is supported by the national government. However, lack of scientific validations have created suspicion on the usage of certain wild animals and plants in the TCM. In India, traditional medicinal practice systems, e.g., Ayurveda, Unani, and Siddha prescribe several traditional medicines against viral diseases, particularly for boosting immunity. Acetogenin, a compound found in papaya leaf helps in preventing disease such as malaria and dengue. Medical practitioners recommend administering papaya leaf extract, which is commercially marketed, in capsules as effective cures for dengue. Papain and alkaloids are nutrients, which act as strong antioxidants, and in turn, enhance the body's immunity. During the current outbreak of SARS-CoV-2, the Indian government had recommended the public to take "kadha" which contains a wide spectrum of plant-based extracts and dry spices. In Tamil Nadu state, the government, in fight against COVID-19, freely distributed to public, Kabasura kudineer, an herbal formulation, which contains T.chebula as one of its important herbal constituents. However, systematic scientific validations for most of their derived phytomolecules are yet to be conducted. Systematic research in phytomolecular pathways of acting on enveloped protein molecules and potential of preferential binding to the receptor cells in the humans could result in searching robust answers to combating deadly viruses with the significant benefits of minimizing the side effects. Since in practice, plant-based drugs and immunity boosters use a broad combination, computation approaches through in silico approach can produce high accuracy in determining individual pathway mechanisms.

The research outcomes of phytomolecular investigations using the in silico approach, in vitro and in vivo approaches have potential to create a new health development regime not for the humans alone, but also for the domestic and wild animals in India and across the world. Deaths of Asiatic lions (Panthera leo leo) in few zoos in India recently due to suspected COVID-19 have raised issue of zoonotic intensity in Asian big cats (ABC). One or two of those Asiatic lions had also tested positive to the canine distemper virus that might have created comorbidity like medical situations. Phytomolecular approach to improving immune response in $\mathrm{ABCs}$ could be a distinct possibility using the network pharmacology pathway and in silico analytics.
Further research in this respect will be able to address the present gaps in identifying plant-based interventions as inhibitors for the structural proteins such as spike, envelope, membrane, and nucleocapsid. Advancements in this research could provide significant tools in epidemiology and could be effectively used in treatments and prophylaxis. With the growing interests of the public and governments, across the world, in improving human and animals' immunity to the lethal viruses, e.g., SARS-CoV-2, investments in resources, time and money, on phytomolecular research could have direct and long term bearing on securing human and animals' health protection regime.

Author Contribution Data collection and Writing of manuscript: VC. Content development and Editing: SKN. Data analysis, Editing and Formatting: KGN. Conceptualization and Drafting: JJ. Overall correction and supervision: WA.

Funding This research did not receive any specific Grant from funding agencies in the public, commercial, or nonprofit sectors.

\section{Declarations}

Conflict of interest The authors declare that there are no conflicts of interest.

\section{References}

1. Amici C, Coro A, Ciucci A, Chiappa L, Castilletti C, Martella V, Decaro N, Buonavoglia C, Capobianchi MR, Santoro M (2006) Indomethacin has a potent antiviral activity against SARS coronavirus. Antivir Ther 11:1021-1030

2. Malik YS, Sircar S, Bhat S, Sharun K, Dhama K, Dadar M, Tiwari R, Chaicumpa W (2020) Emerging novel coronavirus (2019-nCoV)—current scenario, evolutionary perspective based on genome analysis and recent developments. Vet Q 40:68-76. https://doi.org/10.1080/01652176.2020.1727993

3. Huang C, Wang Y, Li X et al (2020) Clinical features of patients infected with 2019 novel coronavirus in Wuhan, China. Lancet 395:497-506

4. Ansari A, Burnwal SK (2020) Forecasting, visualization and analysis of COVID-19 in India using time series modelling

5. Walls AC, Park Y-J, Tortorici MA, Wall A, McGuire AT, Veesler D (2020) Structure, function, and antigenicity of the SARS-CoV-2 spike glycoprotein. Cell 181:281-292. https://doi.org/10.1016/j. cell.2020.02.058

6. World Health Organization (UNICEF) UNC (2020) Guidance on developing a national deployment and vaccination plan for COVID-19 vaccines: interim guidance, 16 November 2020. Guid Dev Natl Deploy Vaccin Plan COVID-19 Vaccines Interim Guid, 16 Novemb 2020

7. Mahase E (2020) Coronavirus: covid-19 has killed more people than SARS and MERS combined, despite lower case fatality rate. BMJ 368:m641. https://doi.org/10.1136/bmj.m641

8. Kapoor R, Sharma B, Kanwar S (2017) Antiviral phytochemicals: an overview. Biochem Physiol Open Access. https://doi.org/10. 4172/2168-9652.1000220 
9. Akram M, Tahir IM, Shah SMA, Mahmood Z, Altaf A, Ahmad K, Munir N, Daniyal M, Nasir S, Mehboob H (2018) Antiviral potential of medicinal plants against HIV, HSV, influenza, hepatitis, and coxsackievirus: a systematic review. Phytother Res 32:811-822. https://doi.org/10.1002/ptr.6024

10. Chattopadhyay D, Naik TN (2007) Antivirals of ethnomedicinal origin: structure-activity relationship and scope. Mini Rev Med Chem 7:275-301. https://doi.org/10.2174/138955707780059844

11. Wu R, Wang L, Kuo HCD, Shannar A, Peter R, Chou PJ, Li S, Hudlikar R, Liu X, Liu Z, Poiani GJ, Amorosa L, Brunetti L, Kong AN (2020) An update on current therapeutic drugs treating COVID-19. Curr Pharmacol Rep 6:56-70. https://doi.org/10. 1007/s40495-020-00216-7

12. Schoeman D, Fielding BC (2019) Coronavirus envelope protein: current knowledge. Virol J 16:69. https://doi.org/10.1186/ s12985-019-1182-0

13. Liu J, Zheng X, Tong Q, Li W, Wang B, Sutter K, Trilling M, Lu M, Dittmer U, Yang D (2020) Overlapping and discrete aspects of the pathology and pathogenesis of the emerging human pathogenic coronaviruses SARS-CoV, MERS-CoV, and 2019-nCoV. J Med Virol 92:491-494. https://doi.org/10.1002/jmv.25709

14. Dai W, Zhang B, Jiang X-M, Su H, Li J, Zhao Y, Xie X, Jin Z, Peng J, Liu F, Li C, Li Y, Bai F, Wang H, Cheng X, Cen X, Hu S, Yang X, Wang J, Liu X, Xiao G, Jiang H, Rao Z, Zhang L-K, Xu Y, Yang H, Liu H (2020) Structure-based design of antiviral drug candidates targeting the SARS-CoV-2 main protease. Science 368:1331-1335. https://doi.org/10.1126/science.abb4489

15. Chandel V, Raj S, Rathi B, Kumar D (2020) In silico identification of potent COVID-19 main protease inhibitors from FDA approved antiviral compounds and active phytochemicals through molecular docking: a drug repurposing approach. https://doi.org/10.20944/ preprints202003.0349.v1

16. Patel B, Sharma S, Nair N, Majeed J, Goyal RK, Dhobi M (2021) Therapeutic opportunities of edible antiviral plants for COVID19. Mol Cell Biochem 476:2345-2364

17. Cinatl J, Morgenstern B, Bauer G, Chandra P, Rabenau H, Doerr H (2003) Glycyrrhizin, an active component of liquorice roots, and replication of SARS-associated coronavirus. The Lancet 361:2045-2046. https://doi.org/10.1016/S0140-6736(03)13615-X

18. Hoever G, Baltina L, Michaelis M, Kondratenko R, Baltina L, Tolstikov GA, Doerr HW, Cinatl J (2005) Antiviral activity of glycyrrhizic acid derivatives against SARS-coronavirus. J Med Chem 48:1256-1259. https://doi.org/10.1021/jm0493008

19. Fiore C, Eisenhut M, Krausse R, Ragazzi E, Pellati D, Armanini D, Bielenberg J (2008) Antiviral effects of Glycyrrhiza species. Phytother Res 22:141-148. https://doi.org/10.1002/ptr.2295

20. Xiang Y-Z, Shang H-C, Gao X-M, Zhang B-L (2008) A comparison of the ancient use of ginseng in traditional Chinese medicine with modern pharmacological experiments and clinical trials. Phytother Res 22:851-858. https://doi.org/10.1002/ptr.2384

21. Park HJ, Kim DH, Park SJ, Kim JM, Ryu JH (2012) Ginseng in traditional herbal prescriptions. J Ginseng Res 36:225-241. https://doi.org/10.5142/jgr.2012.36.3.225

22. Chen F, Chan KH, Jiang Y, Kao RY, Lu HT, Fan KW, Cheng VC, Tsui WH, Hung IF, Lee TS, Guan Y, Peiris JS, Yuen KY (2004) In vitro susceptibility of 10 clinical isolates of SARS coronavirus to selected antiviral compounds. J Clin Virol 31:69-75

23. Li S, Chen C, Zhang H, Guo H, Wang H, Wang L, Zhang X, Hua S, Yu J, Xiao P, Li R, Tan X (2005) Identification of natural compounds with antiviral activities against SARS-associated coronavirus. Antiviral Res 67:18-23. https://doi.org/10.1016/j.antiviral. 2005.02.007

24. Nie C, Trimpert J, Moon S, Haag R, Gilmore K, Kaufer BB, Seeberger PH (2021) In vitro efficacy of Artemisia extracts against SARS-CoV-2. Biorxiv preprint. https://doi.org/10.1101/2021.02. 14.431122
25. Nair MS, Huang Y, Fidock DA, Polyak SJ, Wagoner J, Towler MJ, Weathers PJ (2021) Artemisia annua L. extracts inhibit the in vitro replication of SARS-CoV-2 and two of its variants. J Ethnopharmacol 274:114016. https://doi.org/10.1016/j.jep. 2021.114016

26. Day CW, Baric R, Cai SX, Frieman M, Kumaki Y, Morrey J, Smee D, Barnard DL (2009) A new mouse-adapted strain of SARS-CoV as a lethal model for evaluating antiviral agents in vitro and in vivo. Virology 395(2):210-222

27. Lin S-C, Ho C-T, Chuo W-H, Li S, Wang TT, Lin C-C (2017) Effective inhibition of MERS-CoV infection by resveratrol. BMC Infect Dis 17:144. https://doi.org/10.1186/s12879-017-2253-8

28. Müller C, Schulte FW, Lange-Grünweller K, Obermann W, Madhugiri R, Pleschka S, Ziebuhr J, Hartmann RK, Grünweller A (2018) Broad-spectrum antiviral activity of the eIF4A inhibitor silvestrol against corona- and picornaviruses. Antiviral Res 150:123-129. https://doi.org/10.1016/j.antiviral.2017.12.010

29. Lin L-T, Hsu W-C, Lin C-C (2014) Antiviral natural products and herbal medicines. J Tradit Complement Med 4:24-35. https://doi. org/10.4103/2225-4110.124335

30. Chiow KH, Phoon MC, Putti T, Tan BKH, Chow VT (2016) Evaluation of antiviral activities of Houttuynia cordata Thunb. extract, quercetin, quercetrin and cinanserin on murine coronavirus and dengue virus infection. Asian Pac J Trop Med 9:1-7. https://doi. org/10.1016/j.apjtm.2015.12.002

31. Signer J, Jonsdottir HR, Albrich WC, Strasser M, Züst R, Ryter S, Ackermann-Gäumann R, Lenz N, Siegrist D, Suter A, Schoop R, Engler OB (2020) In vitro virucidal activity of Echinaforce ${ }^{\circledR}$, an Echinacea purpurea preparation, against coronaviruses, including common cold coronavirus 229E and SARS-CoV-2. In review. Virol J 17(1):1-11

32. Ahmed HM (2019) Ethnomedicinal, phytochemical and pharmacological investigations of Perilla frutescens (L.) Britt. Molecules 24:102. https://doi.org/10.3390/molecules24010102

33. Keyaerts E, Vijgen L, Pannecouque C, Van Damme E, Peumans W, Egberink H, Balzarini J, Van Ranst M (2007) Plant lectins are potent inhibitors of coronaviruses by interfering with two targets in the viral replication cycle. Antiviral Res 75:179-187. https:// doi.org/10.1016/j.antiviral.2007.03.003

34. Naithani R, Huma LC, Holland LE, Shukla D, McCormick DL, Mehta RG, Moriarty RM (2008) Antiviral activity of phytochemicals: a comprehensive review. Mini Rev Med Chem 8:1106-1133. https://doi.org/10.2174/138955708785909943

35. O'Keefe BR, Giomarelli B, Barnard DL, Shenoy SR, Chan PKS, McMahon JB, Palmer KE, Barnett BW, Meyerholz DK, WohlfordLenane CL, McCray PB (2010) Broad-spectrum in vitro activity and in vivo efficacy of the antiviral protein griffithsin against emerging viruses of the family Coronaviridae. J Virol 84:25112521. https://doi.org/10.1128/JVI.02322-09

36. Goc A, Sumera W, Rath M, Niedzwiecki A (2021) Phenolic compounds disrupt spike-mediated receptor-binding and entry of SARS-CoV-2 pseudo virions. PLoS ONE 16(6):e0253489

37. Chung MS, Bae WJ, Choi SW, Lee KW, Jeong HC, Bashraheel F, Jeon SH, Jung JW, Yoon BI, Kwon EB, Oh HA, Hwang SY, Kim SW (2017) An Asian traditional herbal complex containing Houttuynia cordata Thunb, Perilla frutescens Var. acuta and green tea stimulates hair growth in mice. BMC Complement Altern Med 17:515. https://doi.org/10.1186/s12906-017-2003-x

38. Lau K-M, Lee K-M, Koon C-M, Cheung CS-F, Lau C-P, Ho H-M, Lee MY-H, Au SW-N, Cheng CH-K, Lau CB-S, Tsui SK-W, Wan DC-C, Waye MM-Y, Wong K-B, Wong C-K, Lam CW-K, Leung P-C, Fung K-P (2008) Immunomodulatory and anti-SARS activities of Houttuynia cordata. J Ethnopharmacol 118:79-85. https:// doi.org/10.1016/j.jep.2008.03.018

39. Chang S-J, Chang Y-C, Lu K-Z, Tsou Y-Y, Lin C-W (2012) Antiviral activity of Isatis indigotica extract and its derived indirubin 
against Japanese encephalitis virus. Evid Based Complement Altern Med. https://doi.org/10.1155/2012/925830

40. Lin C-W, Tsai F-J, Tsai C-H, Lai C-C, Wan L, Ho T-Y, Hsieh C-C, Chao P-DL (2005) Anti-SARS coronavirus 3C-like protease effects of Isatis indigotica root and plant-derived phenolic compounds. Antiviral Res 68:36-42. https://doi.org/10.1016/j.antiv iral.2005.07.002

41. (2020) Redeploying plant defences. Nat Plants 6:177. https://doi. org/10.1038/s41477-020-0628-0

42. Wen C-C, Kuo Y-H, Jan J-T, Liang P-H, Wang S-Y, Liu H-G, Lee C-K, Chang S-T, Kuo C-J, Lee S-S, Hou C-C, Hsiao P-W, Chien S-C, Shyur L-F, Yang N-S (2007) Specific plant terpenoids and lignoids possess potent antiviral activities against severe acute respiratory syndrome coronavirus. J Med Chem 50:4087-4095. https://doi.org/10.1021/jm070295s

43. Ryu YB, Jeong HJ, Kim JH, Kim YM, Park J-Y, Kim D, Naguyen TTH, Park S-J, Chang JS, Park KH, Rho M-C, Lee WS (2010) Biflavonoids from Torreya nucifera displaying SARS-CoV 3CLpro inhibition. Bioorg Med Chem 18:7940-7947. https://doi. org/10.1016/j.bmc.2010.09.035

44. Wen C-C, Shyur L-F, Jan J-T, Liang P-H, Kuo C-J, Arulselvan P, Wu J-B, Kuo S-C, Yang N-S (2011) Traditional Chinese medicine herbal extracts of Cibotium barometz, Gentiana scabra, Dioscorea batatas, Cassia tora, and Taxillus chinensis inhibit SARS-CoV replication. J Tradit Complement Med 1:41-50. https://doi.org/ 10.1016/S2225-4110(16)30055-4

45. Cho JK, Curtis-Long MJ, Lee KH, Kim DW, Ryu HW, Yuk HJ, Park KH (2013) Geranylated flavonoids displaying SARS-CoV papain-like protease inhibition from the fruits of Paulownia tomentosa. Bioorg Med Chem 21:3051-3057. https://doi.org/10. 1016/j.bmc.2013.03.027

46. Park J-Y, Ko J-A, Kim DW, Kim YM, Kwon H-J, Jeong HJ, Kim CY, Park KH, Lee WS, Ryu YB (2016) Chalcones isolated from Angelica keiskei inhibit cysteine proteases of SARS-CoV. J Enzyme Inhib Med Chem 31:23-30. https://doi.org/10.3109/ 14756366.2014.1003215

47. Tripathi MK, Singh P, Sharma S, Singh TP, Ethayathulla AS, Kaur P (2020) Identification of bioactive molecular from Withania somnifera (Ashwagandha) as SARS-CoV-2 main protease inhibitor. J Biomol Struct Dyn. https://doi.org/10.1080/07391102.2020. 1790425

48. Matveeva T, Khafizova G, Sokomova S (2020) In search of herbal anti-SARS-CoV2 compounds. Front Plant Sci 11:589998

49. Krupanidhi S, Peele KA, Venkateswarulu TC, Ayyagiri VS, Bobby MN, Babu DJ, Narayana AV, Aishwarya G (2020) Screening of phytochemical compounds of Tinospora cordifolia for their inhibitory activity on SARS-CoV-2: an in silico study. J Biomol Struct Dyn. https://doi.org/10.1080/07391102.2020.1787226

50. Liu X, Raghuvanshi R, Ceylan FD, Bolling BW (2020) Quercetin and its metabolites inhibit recombinant human angiotensin-converting enzyme 2 (ACE2) activity. J Agric Food Chem 68:13982-13989

51. Khanna K, Kohli SK, Kaur R, Bhardwaj A, Bhardwaj V, Ohri P, Sharma A, Ahmad A, Bhardwaj R, Ahmad P (2021) Herbal immune-boosters: substantial warriors of pandemic COID-19 battle. Phy Med 85:153361

52. Schwarz S, Sauter D, Wang K, Zhang R, Sun B, Karioti A, Bilia AR, Efferth T, Schwarz W (2014) Kaempferol derivatives as antiviral drugs against the 3 a channel protein of coronavirus. Planta Med 80:177-182

53. Cherian SS, Agrawal M, Basu A, Abraham P, Gangakhedkar RR, Bhargava B (2020) Perspectives for repurposing drugs for the coronavirus disease 2019. Indian J Med Res 151:160. https://doi. org/10.4103/ijmr.IJMR_585_20

54. Tahir ul Qamar M, Alqahtani SM, Alamri MA, Chen L-L (2020) Structural basis of SARS-CoV-2 3CLpro and anti-COVID-19 drug discovery from medicinal plants. J Pharm Anal 10:313319. https://doi.org/10.1016/j.jpha.2020.03.009

55. Enmozhi SK, Raja K, Sebastine I, Joseph J (2020) Andrographolide as a potential inhibitor of SARS-CoV-2 main protease: an in silico approach. J Biomol Struct Dyn. https://doi. org/10.1080/07391102.2020.1760136

56. Patwardhan B, Chandran U (2015) Network ethnopharmacology approaches for formulation discovery. IJTK, vol 144, Oct 2015

57. Zhang R, Zhu X, Bai H, Ning K (2019) Network pharmacology databases for traditional Chinese medicine: review and assessment. Front Pharmacol. https://doi.org/10.3389/fphar.2019. 00123

58. Zhang X, Gu J, Cao L, Li N, Ma Y, Su Z, Ding G, Chen L, Xu X, Xiao W (2014) Network pharmacology study on the mechanism of traditional Chinese medicine for upper respiratory tract infection. Mol Biosyst 10:2517-2525. https://doi.org/10.1039/ C4MB00164H

59. Yu S, Wang J, Shen H (2020) Network pharmacology-based analysis of the role of traditional Chinese herbal medicines in the treatment of COVID-19. Ann Palliat Med 9:437-446. https://doi.org/10.21037/apm.2020.03.27

60. van der Hoek L, Pyrc K, Jebbink MF, Vermeulen-Oost W, Berkhout RJM, Wolthers KC, Wertheim-van Dillen PME, Kaandorp J, Spaargaren J, Berkhout B (2004) Identification of a new human coronavirus. Nat Med 10:368-373. https://doi.org/10. 1038/nm10

61. Ganjhu RK, Mudgal PP, Maity H, Dowarha D, Devadiga S, Nag S, Arunkumar G (2015) Herbal plants and plant preparations as remedial approach for viral diseases. Virus Dis 26:225-236. https://doi.org/10.1007/s13337-015-0276-6

62. Jia Y, Xu R, Hu Y, Zhu T, Ma T, Wu H, Hu L (2016) Anti-NDV activity of baicalin from a traditional Chinese medicine in vitro. J Vet Med Sci. https://doi.org/10.1292/jvms.15-0572

63. Li T, Peng T (2013) Traditional Chinese herbal medicine as a source of molecules with antiviral activity. Antiviral Res 97:1-9. https://doi.org/10.1016/j.antiviral.2012.10.006

64. Moghaddam E, Teoh B-T, Sam S-S, Lani R, Hassandarvish P, Chik Z, Yueh A, Abubakar S, Zandi K (2014) Baicalin, a metabolite of baicalein with antiviral activity against dengue virus. Sci Rep 4:5452. https://doi.org/10.1038/srep05452

65. Chu M, Xu L, Zhang M, Chu Z, Wang Y (2015) Role of Baicalin in anti-influenza virus $A$ as a potent inducer of IFN-gamma. BioMed Res Int. https://doi.org/10.1155/2015/263630

66. Zhang H, Li C, Kwok S-T, Zhang Q-W, Chan S-W (2013) A review of the pharmacological effects of the dried root of Polygonum cuspidatum (Hu Zhang) and its constituents. Evid Based Complement Alternat Med. https://doi.org/10.1155/2013/208349

67. Wang Q-W, Su Y, Sheng J-T, Gu L-M, Zhao Y, Chen X-X, Chen C, Li W-Z, Li K-S, Dai J-P (2018) Anti-influenza A virus activity of rhein through regulating oxidative stress, TLR4, Akt, MAPK,

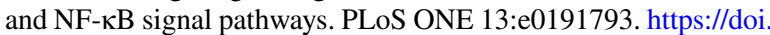
org/10.1371/journal.pone.0191793

68. Reddy DB, Reddy TCM, Jyotsna G, Sharan S, Priya N, Lakshmipathi V, Reddanna P (2009) Chebulagic acid, a COX-LOX dual inhibitor isolated from the fruits of Terminalia chebula Retz., induces apoptosis in COLO-205 cell line. J Ethnopharmacol 124:506-512. https://doi.org/10.1016/j.jep.2009.05.022

69. Bag A, Bhattacharyya SK, Chattopadhyay RR (2013) The development of Terminalia chebula Retz. (Combretaceae) in clinical research. Asian Pac J Trop Biomed 3:244-252. https://doi.org/10. 1016/S2221-1691(13)60059-3

70. Lin L-T, Chen T-Y, Lin S-C, Chung C-Y, Lin T-C, Wang G-H, Anderson R, Lin C-C, Richardson CD (2013) Broad-spectrum antiviral activity of chebulagic acid and punicalagin against viruses that use glycosaminoglycans for entry. BMC Microbiol 13:187. https://doi.org/10.1186/1471-2180-13-187 
71. Aher V, Wahi A (2011) Immunomodulatory activity of alcohol extract of Terminalia chebula Retz Combretaceae. Trop J Pharm Res 10:567-575. https://doi.org/10.4314/tjpr.v10i5.5

72. Samy RP, Thwin MM, Gopalakrishnakone P (2007) Phytochemistry, pharmacology and clinical use of Andrographis paniculata. Nat Prod Commun 2:1934578X0700200519. https://doi.org/10. 1177/1934578X0700200519

73. Panraksa P, Ramphan S, Khongwichit S, Smith DR (2017) Activity of andrographolide against dengue virus. Antiviral Res 139:69-78. https://doi.org/10.1016/j.antiviral.2016.12.014

74. Gupta S, Mishra KP, Ganju L (2017) Broad-spectrum antiviral properties of andrographolide. Arch Virol 162:611-623. https:// doi.org/10.1007/s00705-016-3166-3

75. Puri A, Saxena R, Saxena RP, Saxena KC, Srivastava V, Tandon JS (2004) Immunostimulant agents from Andrographis paniculata. J Nat Prod 56(7):995-999. https://doi.org/10.1021/np500 $97 \mathrm{a} 002$

76. El-Saber Batiha G, Magdy Beshbishy A, El-Mleeh A, Abdel-Daim MM, Prasad Devkota H (2020) Traditional uses, bioactive chemical constituents, and pharmacological and toxicological activities of Glycyrrhiza glabra L. (Fabaceae). Biomolecules 10:352. https://doi.org/10.3390/biom10030352

77. Wang L, Yang R, Yuan B, Liu Y, Liu C (2015) The antiviral and antimicrobial activities of licorice, a widely-used Chinese herb. Acta Pharm Sin B 5:310-315. https://doi.org/10.1016/j.apsb.2015. 05.005

78. Anagha K, Deshpande DM, Priya L, Meera M (2014) Scope of Glycyrrhiza glabra (Yashtimadhu) as an antiviral agent: a review. Int J Curr Microbiol Appl Sci 3(12):657-665

79. Bordbar N, Karimi MH, Amirghofran Z (2012) The effect of glycyrrhizin on maturation and $\mathrm{T}$ cell stimulating activity of dendritic cells. Cell Immunol 280:44-49. https://doi.org/10.1016/j.cellimm. 2012.11.013

80. Soufy H, Yassein S, Ahmed AR, Khodier MH, Kutkat MA, Nasr SM, Okda FA (2012) Antiviral and immune stimulant activities of glycyrrhizin against duck hepatitis virus. Afr J Tradit Complement Altern Med 9:389-395. https://doi.org/10.4314/ajtcam.v9i3.14

81. Visalli RJ, Ziobrowski H, Badri KR, He JJ, Zhang X, Arumugam SR, Zhao H (2015) Ionic derivatives of betulinic acid exhibit antiviral activity against herpes simplex virus type-2 (HSV-2), but not HIV-1 reverse transcriptase. Bioorg Med Chem Lett 25:31683171. https://doi.org/10.1016/j.bmcl.2015.05.099

82. Yi J, Obminska-Mrukowicz B, Yuan L, Yuan H (2010) Immunomodulatory effects of betulinic acid from the bark of white birch on mice. J Vet Sci 11:305-313. https://doi.org/10.4142/jvs. 2010.11.4.305

83. Harun NH, Septama AW, Ahmad WANW, Suppian R (2020) Immunomodulatory effects and structure-activity relationship of botanical pentacyclic triterpenes: a review. Chin Herb Med 12:118-124. https://doi.org/10.1016/j.chmed.2019.11.007

84. Wu CY, Jan JT, Ma SH, Kuo CJ, Juan HF et al (2004) Small molecules targeting severe acute respiratory syndrome human coronavirus. Proc Natl Acad Sci USA 101:10012-10017

85. He R, Adonov A, Traykova-Adonova M, Cao J, Cutts T, Grudesky E, Deschambaul Y, Berry J, Drebot M, Li X (2004) Potent and selective inhibition of SARS coronavirus replication by aurintricarboxylic acid. Biochem Biophys Res Commun 320:1199-1203

86. Xiao S, Tian Z, Wang Y, Si L, Zhang L, Zhou D (2018) Recent progress in the antiviral activity and mechanism study of pentacyclic triterpenoids and their derivatives. Med Res Rev 38:951-976. https://doi.org/10.1002/med.21484

87. Sui H, Yu Q, Zhi Y, Geng G, Liu H, Xu H (2010) Effects of apigenin on the expression of angiotensin-converting enzyme 2 in kidney in spontaneously hypertensive rats. J Hyg Res 39:693-696

88. Chen H, Du Q (2020) Potential natural compounds for preventing 2019-nCoV infection. Preprints 358:1-17

89. Utomo RY, Ikawati M, Meiyanto E (2020) Revealing the potency of citrus and galangal constituents to halt SARS-CoV-2 infection. Preprints 214:1-8

90. Ho TY, Wu SL, Chen JC, Li CC, Hsiang CY (2007) Emodin blocks the SARS coronavirus spike protein and angiotensin-converting enzyme 2 interaction. Antivir Res 74(2):92-101. https:// doi.org/10.1016/j.antiviral.2006.04.014

91. Guerrero L, Castillo J, Quinones M, Garcia-Vallve S, Arola L, Pujadas G, Muguerza B (2012) Inhibition of angiotensin-converting enzyme activity by flavonoids: structure-activity relationship studies. PLoS ONE 7:e49493

92. Takahashi S, Yoshiya T, Yoshizawa-Kumagaye K, Sugiyama T (2015) Nicotianamine is a novel angiotensinconverting enzyme 2 inhibitor in soybean. Biomed Res 36:219-222

93. Puttaswamy H, Gowtham HG, Ojha MD, Yadav A, Choudhir G, Raguraman V, Kongkham B, Selvaraju K, Shareef S, Gehlot P, Ahamed F (2020) In silico studies evidenced the role of structurally diverse plant secondary metabolites in reducing SARS-CoV-2 pathogenesis. Sci Rep 10(1):1-24

94. Kumar A, Shasany AK (2020) SARS-CoV-2 pocketome: severe acute respiratory syndrome Coronavirus 2 , pockets identification for antiviral \& antimicrobial phytomolecules and drug repurposing

Publisher's Note Springer Nature remains neutral with regard to jurisdictional claims in published maps and institutional affiliations. 